\title{
Estatísticas sobre irrigação no Brasil segundo o Censo Agropecuário 1995-1996
}

1 UFC. Rua Tito de Barros 431/403, CEP 60864-300, Fortaleza, CE. Fone: (85) 279-4933. E-mail: mloiola@bol.com.br (Foto)
2 UFC. Departamento de Engenharia Agrícola/CCA/UFC. E-mail: fsouza@ufc.br

Protocolo $131-23 / 10 / 2000$

\begin{abstract}
Resumo: Neste trabalho utilizam-se dados do Censo Agropecuário 1995-1996, para se avaliar a irrigação no país, com relação à área irrigada, aos métodos utilizados e aos grupos de área, por região e por estado. A área irrigada no Brasil, de acordo com o Censo Agropecuário 1995-1996, é de 3,1 milhões de hectares, representando apenas 2,1\% dos 146,8 milhões de hectares cultivados com lavouras permanentes, temporárias, pastagens e florestas. A região Sul apresenta a maior área irrigada, 1,1 milhão de ha, equivalente a $35 \%$ da área total irrigada. Em segundo lugar vem a região Sudeste com, aproximadamente, $30 \%$; com $24 \%$ de toda a área irrigada no Brasil, o Nordeste ocupa a terceira posição seguido das regiões Centro-Oeste e Norte, que têm pouca expressão e, juntas, somam cerca de $11 \%$ do total. Nas regiões NE, SE e Sul, a irrigação predomina nos estabelecimentos cuja área é inferior a 1.000 ha. Diferentemente, nas regiões Norte e Centro-Oeste a irrigação é mais significativa nos estabelecimentos com área maior que 10.000 ha. O método de irrigação por superfície, continua a ser o mais utilizado no país $(59 \%)$, nas regiões $\mathrm{NE}$ e Sul, com a aspersão prevalecendo nas demais regiões; a irrigação localizada representa a menor área.
\end{abstract}

Palavras-chave: irrigação, estatística, censo

\section{Statistics on irrigation in Brazil according to the 1995-1996 Agricultural Census}

\begin{abstract}
This paper uses the 1995-1996 of agricultural census data to evaluate irrigation in Brazil in relation to the irrigated areas and irrigation methods by groups, region and states. Based on this, Brazil has 3.1 million hectares under irrigation, corresponding to only $2.1 \%$ of the 146.8 million hectare of cultivated area with annual and permanent crops, pastures and forests. The southern region presents the largest irrigated area, 1.1 million ha, corresponding to $35 \%$ of the total irrigated area. The second largest irrigated area is in the southeastern region (30\%), followed by the northeast $(24 \%)$; the centre-western and north have, together by $11 \%$ of the total area. Irrigated farms smaller than 1,000 ha predominate in the northeast, southeast and south regions. In the centre-west and north irrigation is more important in farms larger than 10,000 ha. Surface irrigation is the most used irrigation method (59\% of the farms) in the northeast and south; sprinkler irrigation predominates in the remaining regions, while trickle irrigation represents the smallest area.
\end{abstract}

Key words: irrigation, statistics, census

\section{INTRODUÇÃO}

De acordo com o Banco Mundial (1990) o potencial de irrigação do Brasil é estimado em cerca de 29 milhões de hectares, excluídas as bacias do Amazonas e do Tocantins, na região Norte. No entanto, em 1998 a área irrigada era de apenas 2,87 milhões de hectares (Christofidis, 1999).

Para se avaliar o que representa a extensão da área irrigada do Brasil, apresentam-se algumas informações sobre irrigação em alguns países. De acordo com Hernando (1998) utilizando dados de 1992 da FAO, a área total irrigada no mundo girava em torno de 250 milhões de hectares, com o Brasil ocupando o $13^{\circ}$ lugar, atrás da China ( $1^{\circ}$ colocado, com 49,9 milhões de ha), Estados Unidos ( $4^{\circ}$ colocado, com 20,4 milhões de ha), México ( $8^{\circ}$ lugar, 6,1 milhões de ha) e Espanha ( $11^{\circ}$ lugar, país com a maior superfície irrigada da Europa, com 3,4 milhões de ha)

A evolução da área irrigada no Brasil tem sido lenta, enquanto as estatísticas são conflitantes. De acordo com a "Resenha Setorial da Irrigação no Brasil" (Brasil, 1989) a área irrigada no país aumentou de 0,4 milhões de hectares em 1960, para 0,5 milhões em 1970, 1,0 milhão em 1980 e 2,3 milhões de hectares em 1988. Cerca de $94 \%$ das áreas irrigadas foram desenvolvidos pela iniciativa privada, e os restantes $6 \%$ são projetos públicos. 
Em levantamentos realizados junto aos estados, Christofidis (1999) concluiu que a área irrigada no Brasil era, em 1996, de 2.661.000 ha, em 1997 de 2.765.000 ha, enquanto os dados estimados para 1998 indicavam 2.870 .000 ha. O autor mostra que o método de irrigação por superfície continua a ser o mais utilizado no país, com cerca de 1,7 milhões de hectares (59\%), predominante nas regiões Norte e Sul, enquanto a irrigação por aspersão prevalece nas demais regiões (35\%) e a localizada representa a menor área, com $182 \mathrm{mil} \mathrm{ha} \mathrm{em} \mathrm{fase} \mathrm{de} \mathrm{crescimento,}$ especialmente nas regiões NE e SE. A maior área irrigada encontra-se na região Sul (1.195.440 ha) seguida do SE (890.974 ha) e do NE com (495.370 ha).

De acordo com Souza et al. (1994) ao se analisar a base de dados sobre a agricultura irrigada no NE, o tamanho da área irrigada é uma das mais importantes informações sobre a agricultura irrigada. É com base nesse parâmetro que se pode planejar a sua expansão. Esse mesmo autor cita quatro fontes de informações sobre área irrigada: o Censo Agropecuário; o Cadastro Nacional de Irrigantes da Secretaria de Irrigação do Ministério da Integração Nacional; o processamento feito pelo Banco do Nordeste do Brasil (BNB) e as estatísticas produzidas pelos órgãos responsáveis pela irrigação pública federal CODEVASF e DNOCS. Acrescente-se, a esta relação, as informações divulgadas por órgãos responsáveis pela política agrícola e de irrigação de cada estado. Souza (1994) afirma ainda que, além do tamanho da área irrigada por estabelecimento, para cada município, os Censos Agropecuários registram os tipos de sistema de irrigação, informando o número de estabelecimentos que usam cada sistema sem, contudo, estabelecer qual a área irrigada por cada sistema.

Esta diversidade de fontes vem causando uma série de confusões ao longo do tempo, dando origem a várias interpretações, o que tem causado pouca credibilidade às estatísticas divulgadas sobre irrigação no país.

Para corroborar a confusão estatística causada pela diversidade de fontes, retorna-se a outra citação de Souza et al. (1994): "a pobreza dos dados censitários não permite melhor caracterização da agricultura irrigada na região. Tem havido questionamento até mesmo acerca da dimensão da área irrigada". E ele apresenta um exemplo: "levantamento feito pelo BNB, em 1987, junto aos órgãos de financiamento, ..., identificou a existência de apenas 98.176 ha irrigados, o que representa um pouco mais de $1 / 4$ da área estimada pelo Censo Agropecuário", 336,8 mil ha, cerca de $18 \%$ da área irrigada no Brasil (1.853,7 mil hectares) em 1985. Para tentar explicar o conflito entre as duas fontes de informação, o mesmo autor conclui pela forma de abrangência pois, segundo afirma, no Censo o conceito de irrigação é bastante amplo e abrangente, variando desde o que ele denomina de "molhação", nas margens dos rios e reservatórios (a chamada agricultura de vazante) até o uso de técnicas mais sofisticadas enquanto o BNB/ETENE (Escritório Técnico do Nordeste) se restringe à irrigação propriamente dita (na realidade, as informações do BNB referem-se aos projetos contratados).

Reconhecendo o problema estabelecido com relação às informações sobre irrigação no país e com o propósito de contribuir para o debate sobre a melhoria das estatísticas sobre o assunto, reconhecendo, ainda, a importância dos dados censitários, é que os autores decidiram publicar esta pesquisa sobre as informações estatísticas do Censo Agropecuário 19951996, cujos resultados são apresentados de acordo com a indicação de uso da irrigação e área irrigada por estado de cada região e segundo os grupos de área, considerando-se os estabelecimentos informantes do uso dos diferentes métodos de irrigação.

\section{MATERIAL E MÉTODOS}

A pesquisa foi realizada utilizando-se dados retirados da Tabela 8 do CD-ROM do Censo Agropecuário 1995-1996 (IBGE, 1998), a qual se refere aos estabelecimentos com indicação de uso de irrigação e área irrigada, segundo a condição do produtor, o grupo da atividade econômica, assistência técnica e grupos de área total. Os dados da tabela foram organizados em duas etapas, em que a primeira compara a área irrigada e a porcentagem dos métodos de irrigação das grandes regiões do Brasil e, dentro da região, confronta os estados, sem considerar o tamanho dos estabelecimentos; a segunda etapa acrescenta um parâmetro de fundamental importância, o tamanho do estabelecimento que utiliza irrigação, mantendo o confronto entre estados dentro das grandes regiões do país. Estas informações foram comparadas aos dados publicados na escassa literatura existente.

A planilha MS-Excel, versão 97, foi utilizada para construção dos gráficos, que mostram as porcentagens de área irrigada nas grandes regiões e as porcentagens de uso dos métodos de irrigação nas regiões e nos estados brasileiros. É importante lembrar que, tanto para as regiões como para os estados, os métodos de irrigação por inundação e infiltração foram somados para representar o método de irrigação por superfície.

\section{RESULTADOS E DISCUSSÃO}

\section{Área irrigada por região}

De acordo com o Censo Agropecuário 1995-1996, o Brasil apresentava 3,1 milhões de hectares cultivados com irrigação. A região Sul é a mais expressiva com, 1,1 milhão de hectares, equivalente a $35 \%$ da área total irrigada no país; em segundo lugar vem a região Sudeste com, aproximadamente, $30 \%$, enquanto com $24 \%$ de toda área irrigada no Brasil, o NE se coloca na terceira posição, seguido das regiões Centro-Oeste e Norte, que têm pouca expressão e, juntas, somam cerca de $11 \%$ do total (Tabela 1). Esses dados diferem daqueles publicados por Christofidis (1999) segundo o qual a área irrigada no país evoluiu do seguinte modo: 2.661 .000 hectares, em 1996; 2.765 .000 em 1997 e 2.870 .000 em 1998.

Tabela 1. Distribuição percentual da irrigação nas regiões brasileiras, segundo o Censo Agropecuário 1995-1996

\begin{tabular}{lcr}
\hline Região & Área Irrigada (ha) & \multicolumn{1}{c}{$(\%)$} \\
\hline Sul & 1.096 .592 & 35,1 \\
Sudeste & 929.189 & 29,8 \\
Nordeste & 751.882 & 24,1 \\
Centro Oeste & 260.953 & 8,4 \\
Norte & 83.023 & 2,7 \\
Total & 3.121 .644 & 100,00 \\
\hline
\end{tabular}


Com relação aos métodos de irrigação, os dados censitários mostram que os métodos por superfície predominam nas regiões $\mathrm{NE}(56,8 \%)$ e $\operatorname{Sul}(57,2 \%)$ enquanto a aspersão é predominante no $\mathrm{SE}(61,6 \%)$ e no Centro-Oeste $(57,7 \%)$. Estes resultados estão de acordo com Christofidis (1999) e podem ser observados na Tabela 2.

Tabela 2. Distribuição percentual da irrigação pelos diferentes métodos nas regiões brasileiras, segundo o Censo Agropecuário 1995/96

\begin{tabular}{lccr}
\hline \multirow{2}{*}{ Região } & \multicolumn{3}{c}{ Métodos - \% } \\
\cline { 2 - 4 } & Superfície & Aspersão & Outros \\
\hline Nordeste & 56,83 & 35,82 & 7,35 \\
Sudeste & 33,07 & 61,63 & 5,30 \\
Sul & 57,23 & 37,10 & 5,66 \\
Centro-Oeste & 36,87 & 57,67 & 5,46 \\
Norte & 41,41 & 45,55 & 13,03 \\
\hline
\end{tabular}

Indicação de uso da irrigação e área irrigada por estado, Região Nordeste

Na Tabela 3A são apresentados os indicadores de uso de irrigação e área irrigada por estado da região NE do Brasil. A área irrigada nessa região totaliza 751.887 ha, o que representa $24 \%$ de toda a área irrigada no país; a Bahia apresenta a maior área irrigada (209.705ha) da região e a menor é o Estado de Sergipe (13.691ha) correspondendo a $28 \%$ e $1,8 \%$, respectivamente. O Ceará, com $14,5 \%$ do total, ocupa a quarta posição na região (108.998ha).

Dos 2.326.413 estabelecimentos agropecuários do NE, apenas 98.204 fazem uso da irrigação, representando somente $4,2 \%$ do total. Quando se analisa isoladamente constata-se que o método mais usado é o de aspersão, seguido pelos métodos de irrigação por sulco e inundação, representando 35,8\%, 32,2\% e $24,5 \%$, respectivamente. Cerca de $7,5 \%$ dos estabelecimentos irrigam por outros métodos.

Tabela 3. Indicação de uso de irrigação e área irrigada, por Estado nas diferentes regiões do Brasil ${ }^{1}$

\begin{tabular}{|c|c|c|c|c|c|c|c|c|}
\hline \multirow{3}{*}{ Estado } & \multirow{3}{*}{$\begin{array}{c}\text { Total de } \\
\text { Estabelecimentos }\end{array}$} & \multicolumn{5}{|c|}{ Estabelecimentos Informantes } & \multicolumn{2}{|c|}{ Área Irrigada } \\
\hline & & \multirow{2}{*}{ Total $(*)$} & \multicolumn{4}{|c|}{ Método de Irrigação } & \multirow{2}{*}{ Informantes } & \multirow{2}{*}{ Área (ha) } \\
\hline & & & Inundação & Infiltração & Aspersão & Outros & & \\
\hline \multicolumn{9}{|c|}{ A. Região Nordeste } \\
\hline $\mathrm{AL}$ & 115.064 & 2.891 & 1.219 & 570 & 1.168 & 227 & 2.221 & 156.992 \\
\hline BA & 699.126 & 33.876 & 7.596 & 16.863 & 9.728 & 2.581 & 27.964 & 209.705 \\
\hline $\mathrm{CE}$ & 339.602 & 29.030 & 10.260 & 7.499 & 10.812 & 3.648 & 25.234 & 108.998 \\
\hline MA & 368.191 & 3.514 & 1.627 & 354 & 1.258 & 410 & 2.554 & 16.521 \\
\hline PB & 146.539 & 9.145 & 2.683 & 2.379 & 4.866 & 462 & 7.955 & 63.548 \\
\hline PE & 258.630 & 20.679 & 1.121 & 10.184 & 9.969 & 729 & 18.801 & 118.400 \\
\hline PI & 208.111 & 4.929 & 2.617 & 908 & 1.418 & 307 & 4.715 & 18.254 \\
\hline $\mathrm{RN}$ & 91.376 & 6.158 & 1.932 & 1.017 & 3.260 & 569 & 5.307 & 45.778 \\
\hline SE & 99.774 & 3.863 & 1.418 & 417 & 2.064 & 201 & 3.453 & 13.691 \\
\hline Total & 2.326 .413 & 114.085 & 30.473 & 40.191 & 44.543 & 9.134 & 98.204 & 751.887 \\
\hline \multicolumn{9}{|c|}{ B. Região Norte } \\
\hline $\mathrm{AC}$ & 23.788 & 126 & 32 & 23 & 75 & 27 & 39 & 728 \\
\hline AP & 3.349 & 61 & - & 5 & 56 & - & 53 & 9.119 \\
\hline $\mathrm{AM}$ & 83.289 & 113 & 38 & 9 & 49 & 27 & 58 & 209 \\
\hline $\mathrm{PA}$ & 206.404 & 1.113 & 240 & 243 & 652 & 161 & 473 & 4.797 \\
\hline RO & 76.956 & 671 & 153 & 155 & 374 & 131 & 367 & 1.041 \\
\hline RR & 7.476 & 272 & 55 & 85 & 143 & 32 & 150 & 5.660 \\
\hline TO & 44.913 & 568 & 108 & 265 & 203 & 66 & 311 & 61.469 \\
\hline Total & 446.175 & 2.924 & 626 & 785 & 1.552 & 444 & 1.451 & 83.023 \\
\hline \multicolumn{9}{|c|}{ C. Região Sudeste } \\
\hline ES & 73.288 & 14.764 & 3.166 & 1.590 & 11.295 & 386 & 13.182 & 92.695 \\
\hline MG & 496.677 & 47.673 & 14.006 & 9.621 & 26.216 & 3.089 & 37.597 & 322.679 \\
\hline $\mathrm{RJ}$ & 53.680 & 12.866 & 2.653 & 1.763 & 8.980 & 295 & 11.647 & 74.761 \\
\hline SP & 218.016 & 29.323 & 2.336 & 2.938 & 24.457 & 2.329 & 23.978 & 439.054 \\
\hline Total & 841.661 & 104.626 & 22.161 & 15.912 & 70.948 & 6.099 & 86.404 & 929.189 \\
\hline \multicolumn{9}{|c|}{ D. Região Centro Oeste } \\
\hline DF & 2.459 & 1.469 & 37 & 200 & 1.291 & 101 & 1.377 & 12.591 \\
\hline GO & 111.791 & 6.750 & 227 & 2.738 & 4.156 & 322 & 4.869 & 115.908 \\
\hline MT & 78.763 & 1.048 & 34 & 228 & 756 & 127 & 721 & 59.226 \\
\hline MS & 49.423 & 1.430 & 646 & 231 & 588 & 93 & 1.009 & 73.228 \\
\hline Total & 242.436 & 10.697 & 944 & 3.397 & 6.791 & 643 & 7.976 & 260.953 \\
\hline \multicolumn{9}{|l|}{ E. Sul } \\
\hline PR & 369.875 & 13.518 & 4.559 & 3.017 & 7.856 & 1.456 & 7.857 & 46.890 \\
\hline RS & 429.958 & 26.814 & 16.001 & 2.450 & 9.330 & 1.527 & 22.437 & 935.677 \\
\hline $\mathrm{SC}$ & 203.347 & 13.475 & 7.766 & 811 & 5.247 & 442 & 12.013 & 114.025 \\
\hline Total & 1.003 .180 & 53.807 & 28.326 & 6.278 & 22.433 & 3.425 & 42.307 & 1.096 .592 \\
\hline
\end{tabular}

${ }^{1}$ Fonte: CENSO AGROPECUÁRIO 1995-1996 - NÚMERO 1 - BRASIL

(*) Inclusive os estabelecimentos que declaram mais de um tipo 
Dos 339.602 estabelecimentos do Ceará, apenas 29.030 (8,5\%) praticam irrigação e, neste caso, o método mais utilizado também é a aspersão, seguido pela inundação e depois pela infiltração, compreendendo $34,32 \mathrm{e} 23 \%$, respectivamente. Aproximadamente $11 \%$ dos estabelecimentos irrigam por outros métodos. Vale salientar que o Censo não apresenta dados específicos para os métodos de irrigação localizada (gotejamento e microaspersão) estando os mesmos incluídos na expressão "outros".

A irrigação por superfície, onde estão incluídos os métodos de irrigação por sulcos e por inundação, predomina na região $(56,8 \%)$ quando comparado com os demais, podendo-se afirmar o mesmo quando a análise é feita por estado, com a irrigação por superfície predominando em 7 dos 9 estados da região (AL, BA, CE, MA, PB, PE e PI) (Figura 1A). O Piauí é o estado do NE com o maior percentual de estabelecimentos que utilizam a irrigação por superfície $(67,1 \%)$. Estes dados mostram a extrema importância desses métodos para esta região, indicando a necessidade de pesquisas sobre as formas de se aumentar a eficiência da irrigação por sulco e por inundação.

A área irrigada para a região NE apresentada por Christofidis (1999) para 1996 (428.334 ha)e 1997 (456.020 ha) e a estimativa para 1998 (495.370 ha) são muito inferiores àquelas apresentadas no Censo 1995-1996 (751.887 ha). Deve-se especular, então, sobre essas estatísticas. Houve redução da área irrigada na região ou isto se deve apenas ao fato do Censo utilizar um conceito mais amplo de irrigação, como sugeriu Souza et al. (1994)? É preciso que se analisem, com bastante cuidado, esses aspectos, para que o país possa ser planejado com base em estatísticas confiáveis. Para se obter uma análise por estado, pode-se confrontar os dados apresentados por Christofidis (1999) com a Tabela 3.

\section{Região Norte}

Os indicadores de uso de irrigação e área irrigada por estado da região Norte do Brasil são apresentados na Tabela 3B, com área irrigada de 83.023 ha; trata-se de uma região de pouca expressão em irrigação (representa 2,7\% da área irrigada do país). Outro indicativo dessa pouca expressividade, constata-se ao se comparar o estado com a maior área irrigada nessa região (Tocantins, com 61.469 ha, que corresponde a 74\%) com a maior área irrigada do NE (estado da Bahia com 209.705 ha). A menor área irrigada é a do Amazonas, com apenas 209 ha, representando um percentual ínfimo de $0,2 \%$ do total.

Dos 446.175 estabelecimentos da região Norte do Brasil, apenas 1.451 fazem uso da irrigação, representando somente $0,32 \%$ do total.

O método mais usado é a aspersão, seguido pela infiltração e pela inundação, representando 46, 23 e 18\%, respectivamente. Somente no estado de Tocantins há predominância da irrigação por superfície (Figura 1B), enquanto cerca de 13\% dos estabelecimentos irrigam por outros métodos.

Quando se comparam os dados apresentados por Christofidis (1999) com o Censo (Tabela 3B), para esta região, observa-se que eles são compatíveis, o que coloca em dúvida a tese do amplo conceito do termo irrigação usado no Censo, proposta por Souza et al. (1994).

\section{Região Sudeste}

A Tabela 3C mostra os indicadores de uso de irrigação e a área irrigada por estado da região SE do Brasil, que detém uma
A.

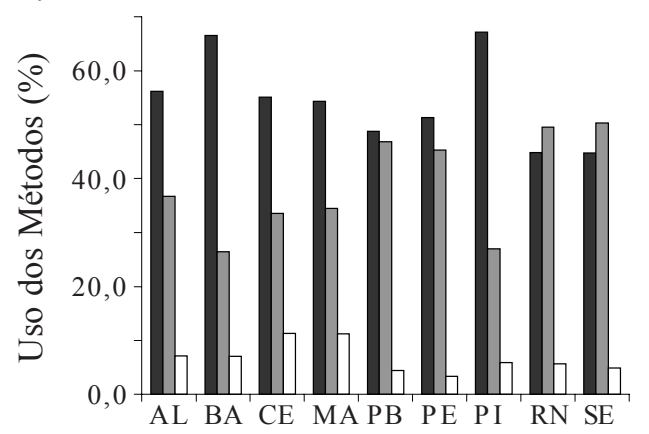

B.

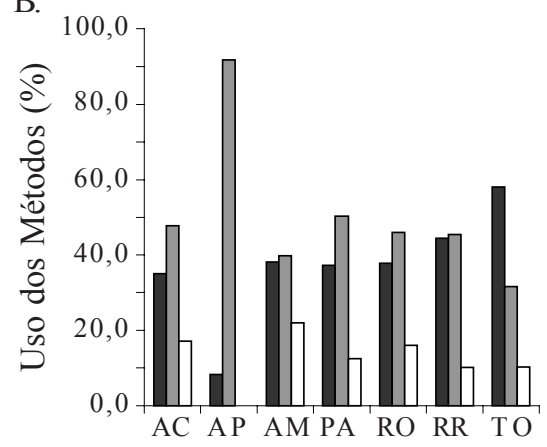

C.

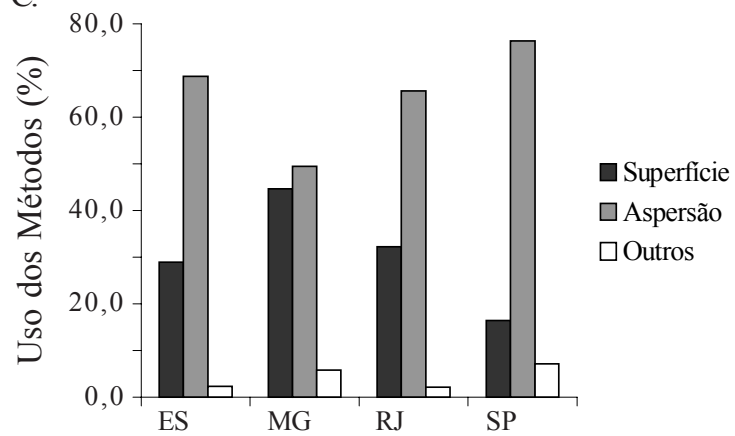

D.

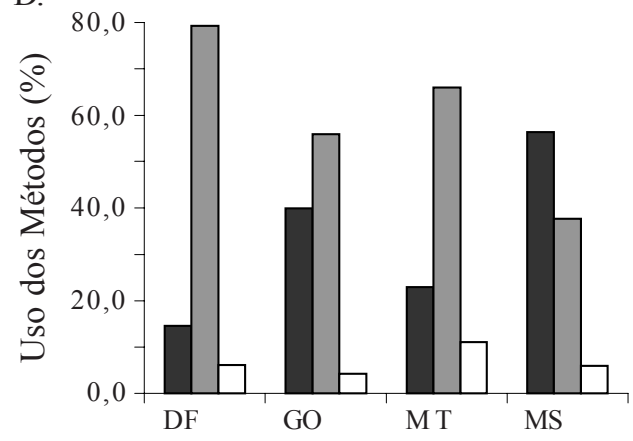

E.

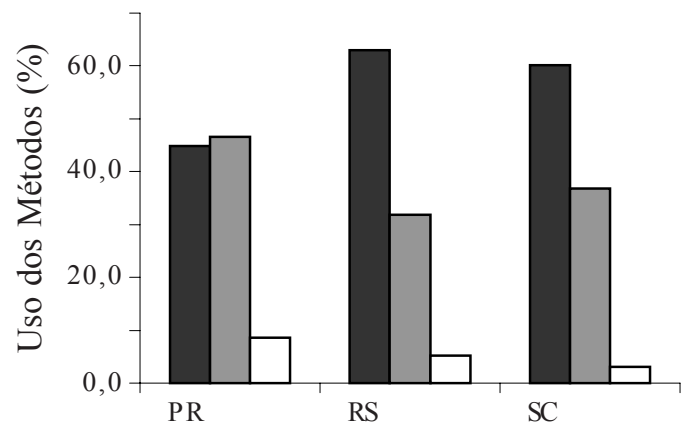

Figura 1. Uso dos métodos de irrigação por Estado nas diferentes regiões do Brasil: A. Nordeste, B. Norte, C. Sudeste, D. Centro-Oeste e E. Sul 
área irrigada de 929.189 ha, representando $30 \%$ de toda a área irrigada no país. São Paulo é o Estado que apresenta a maior área irrigada na região (439.054ha) e o Rio de Janeiro é o que menos irriga (74.761ha) correspondendo a $47 \%$ e $8 \%$, respectivamente; somente 86.404 dos 841.661 estabelecimentos do SE brasileiro utilizam irrigação, representando apenas 10,3\% do total. Quando se analisa o Censo Agropecuário com relação ao uso dos métodos de irrigação, constata-se que esta é uma das regiões do país em que predomina a aspersão $(61,6 \%$ dos estabelecimentos); os métodos por superfície são usados em $32,9 \%$ dos estabelecimentos, sendo $19,2 \%$ por inundação e $13,7 \%$ por sulco (Figura 1C). Cerca de 5,3\% dos estabelecimentos irrigam por outros métodos.

Comparando-se os dados apresentados por Christofidis (1999) para a região SE (821.520 ha, em 1996; 863.816 ha; em 1997; e, 890.974 ha, em 1998) com o Censo (929.189 ha) observa-se pouca discrepância (11,6\% para 1996; 7,0\% para 1997; e, 4,1\% para 1998). O mesmo ocorre quando a análise é feita em relação aos estados da região, porém aquele autor mostra predomínio do método por superfície (Tabela 5). Deve-se considerar que o Censo informa apenas o número de estabelecimentos que cada método utiliza, e não a área irrigada por cada método.

\section{Região Centro-Oeste}

A situação dos indicadores de uso de irrigação e área irrigada por estado da região Centro-Oeste do Brasil, pode ser observada na Tabela 3D, que apresenta área irrigada igual a 260.953 ha. Tal como a região Norte, esta é uma região que também apresenta pouca expressão em irrigação e, quando somadas, as duas representam apenas $11 \%$ da área irrigada no país. Goiás é o Estado com a maior área irrigada (115.908ha) enquanto o Distrito Federal (DF) tem a menor área (12.591ha) correspondendo a 44,4 e $4,8 \%$, respectivamente. Se se considerar o número de estabelecimentos ( $1,0 \%$ do total) e a área ocupada pelo DF, observar-se-á que ele apresenta considerável expressão em irrigação, o que pode ser explicado pela proximidade de Brasília como centro consumidor. A irrigação no DF é praticada, provavelmente, em culturas hortícolas, porque $80 \%$ são feitos pelo método de aspersão.

Dos 242.436 estabelecimentos do Centro-Oeste, apenas 7.976 fazem uso da irrigação, equivalendo a apenas 3,3\% do total. O método mais usado é o de aspersão, seguido pelo de sulcos e o de inundação, representando 58, 29 e 8\%, respectivamente. Cerca de $5 \%$ dos estabelecimentos irrigam por outros métodos (Figura 1D).

Também, neste caso não há grandes diferenças entre os dados do Censo 1995-1996 e aqueles apresentados por Christofidis (1999).

\section{Região Sul}

Na Tabela 3E tem-se os indicadores de uso de irrigação e área irrigada por estado da região Sul, com a maior área irrigada do país (1.096.592ha) representando 35\% do total; o grande destaque é o Estado do Rio Grande do Sul, que irriga 85\% de toda a área ( 935.677 ha). Esses dados são compatíveis com os apresentados por Christofidis (1999). Apenas 42.307 dos 1.003.180 estabelecimentos da região Sul utilizam irrigação, equivalente a $4,2 \%$ do total.
O método mais usado é o de inundação, seguido pelo de aspersão e, depois, pelo de sulco, representando 47, 37,2 e $10 \%$, respectivamente, que se deve ao cultivo da cultura do arroz. Aproximadamente $4 \%$ dos estabelecimentos irrigam por outros métodos (Figura 1E).

\section{Uso da irrigação e área irrigada por estado segundo grupos de área}

\section{Região Nordeste}

$\mathrm{Na}$ Tabela 4A tem-se os estabelecimentos com indicação de uso de irrigação e área total por estado da região $\mathrm{NE}$ do Brasil, segundo grupos de área total. De acordo com o Censo, os grupos de área total estão assim distribuídos: menos de 10 ha, entre 10 e 100 ha, entre 100 e 1.000 ha, entre 1.000 e 10.000 ha e mais de 10.000 ha. Esta forma de distribuição dos grupos de área será considerada na discussão dos resultados para as demais regiões. Com relação à área total irrigada (746.895ha) esses grupos representam 14,4, 18, 30,1, 24,5 e 13\% da área irrigada, respectivamente. Aproximadamente $63 \%$ da área irrigada (467.396 ha) encontram-se nos estabelecimentos com menos de 1.000 ha, enquanto os estabelecimentos com mais de 10.000 ha irrigam apenas $13 \%$ da área total ( $96.724 \mathrm{ha}$ ). Ressalta-se que a área total irrigada apresentada na Tabela 4A (746.895 ha) difere levemente do valor mostrado na Tabela 3 (751.887 ha).

Quando se analisa o número de estabelecimentos que informaram fazer uso da técnica de irrigação (114.060) nota-se que $58 \%$ (66.155) têm menos de 10 ha e apenas $0,1 \%$ (66) mais de 10.000 ha, o que demonstra a importância da pequena propriedade.

Fazendo-se uma análise específica para o Ceará e se utilizando o mesmo raciocínio feito para o NE, os grupos de área total representam 23,8, 30,1,30,4, 14,4 e 1,3\% da área irrigada, respectivamente. Aproximadamente $84 \%$ da área irrigada estão nos estabelecimentos com menos de 1.000 ha. Com relação ao número de estabelecimentos que utilizam a irrigação, o Ceará comporta-se como a região Nordeste, ou seja, $58 \%$ deles têm menos de 10 ha (16.835).

\section{Região Norte}

Os estabelecimentos com indicação de uso de irrigação e área total por estado da região Norte do Brasil, segundo grupos de área total, são apresentados na Tabela 4B. Com relação à área total irrigada, esses grupos apresentam $0,9,3,0,10,8,29,4$ e $55,9 \%$ da área irrigada, respectivamente. Portanto, a maior porcentagem da área irrigada (46.384 ha) encontra-se nos estabelecimentos com área maior que 10.000 ha, enquanto aqueles com menos de $10 \mathrm{ha}$, irrigam apenas $0,9 \% \mathrm{da}$ área total (742 ha) o que permite concluir-se que a região em questão caracteriza-se pela presença de latifúndios, diferentemente da região Nordeste, onde há predominância do minifúndio.

Em relação ao número de estabelecimentos que fazem uso da técnica de irrigação observa-se que 70,4\% têm menos de 100 ha, enquanto apenas $1,0 \%$ possui mais de 10.000 ha.

\section{Região Sudeste}

A Tabela 4C apresenta os estabelecimentos com indicação de uso de irrigação e área total por estado da região SE do Brasil, segundo grupos de área total. Considerando-se a área total irrigada, esses grupos apresentam 7,9, 27,7, 38,5, 20,9 e $5,0 \%$ da área irrigada, respectivamente. Observa-se que a maior 
Tabela 4. Estabelecimentos com indicação de uso de irrigação e área irrigada por estado nas diferentes regiões do Brasil, segundo grupos de área total ${ }^{1}$ (ha)

\begin{tabular}{|c|c|c|c|c|c|c|c|c|}
\hline \multirow{3}{*}{ Estado } & \multirow{3}{*}{$\begin{array}{c}\text { Total de } \\
\text { Estabelecimentos }\end{array}$} & \multicolumn{5}{|c|}{ Estabelecimentos Informantes } & \multicolumn{2}{|c|}{ Área Irrigada } \\
\hline & & \multirow{2}{*}{ Total $(*)$} & \multicolumn{4}{|c|}{ Método de Irrigação } & \multirow{2}{*}{ Informantes } & \multirow{2}{*}{ Área (ha) } \\
\hline & & & Inundação & Infiltração & Aspersão & Outros & & \\
\hline \multicolumn{9}{|c|}{ A. Região Nordeste } \\
\hline \multicolumn{9}{|l|}{$<$ de 10 ha } \\
\hline $\mathrm{AL}$ & 92.736 & 1.328 & 668 & 292 & 385 & 133 & 1.001 & 2.496 \\
\hline BA & 401.734 & 18.908 & 3.923 & 9.840 & 5.095 & 1.382 & 16.167 & 33.063 \\
\hline PB & 101.435 & 3.990 & 1.102 & 1.235 & 1.845 & 252 & 3.464 & 5.378 \\
\hline $\mathrm{PE}$ & 186.669 & 13.354 & 591 & 6.624 & 6.367 & 447 & 12.412 & 25.203 \\
\hline PI & 134.949 & 3.496 & 2.233 & 572 & 633 & 184 & 3.375 & 3.984 \\
\hline $\mathrm{RN}$ & 57.958 & 2.053 & 747 & 296 & 888 & 242 & 1.742 & 3.092 \\
\hline SE & 77.618 & 3.440 & 1310 & 356 & 1.788 & 176 & 3.094 & 6.806 \\
\hline Sub-Total & 1.570 .511 & 66.155 & 18.005 & 24.395 & 22.878 & 5.509 & 58.123 & 107.631 \\
\hline \multicolumn{9}{|l|}{10 a 100 ha } \\
\hline MA & 59.360 & 410 & 123 & 66 & 209 & 38 & 288 & 1.842 \\
\hline PB & 36.840 & 3.680 & 1.160 & 852 & 2.080 & 132 & 3.205 & 12.465 \\
\hline PE & 61.672 & 5.297 & 399 & 2.677 & 2.450 & 204 & 4.639 & 24.652 \\
\hline PI & 55.192 & 790 & 236 & 192 & 379 & 83 & 738 & 2.997 \\
\hline $\mathrm{RN}$ & 26.355 & 2.733 & 808 & 486 & 1.517 & 204 & 2.384 & 10.206 \\
\hline SE & 18.266 & 318 & 88 & 48 & 197 & 17 & 269 & 1.386 \\
\hline Sub-Total & 604.261 & 34.255 & 9.201 & 12.257 & 13.819 & 2646 & 28.835 & 134.776 \\
\hline \multicolumn{9}{|l|}{$100 \mathrm{a} 1.000 \mathrm{ha}$} \\
\hline $\mathrm{AL}$ & 3.487 & 552 & 72 & 82 & 425 & 24 & 439 & 50.858 \\
\hline BA & 41.874 & 3.115 & 680 & 1.129 & 1.432 & 255 & 2.338 & 42.302 \\
\hline $\mathrm{CE}$ & 16.871 & 3.173 & 1.136 & 539 & 1.777 & 261 & 2.668 & 33.110 \\
\hline MA & 20.796 & 269 & 52 & 63 & 152 & 27 & 168 & 4.301 \\
\hline BA & 3.407 & 401 & 65 & 76 & 274 & 38 & 307 & 53.293 \\
\hline $\mathrm{CE}$ & 823 & 308 & 117 & 50 & 188 & 32 & 256 & 15.652 \\
\hline MA & 1.627 & 76 & 13 & 14 & 47 & 9 & 50 & 2.750 \\
\hline PB & 417 & 115 & 25 & 23 & 84 & 7 & 100 & 11.521 \\
\hline $\mathrm{PE}$ & 435 & 159 & 8 & 42 & 121 & 9 & 141 & 19.900 \\
\hline PI & 1.124 & 101 & 25 & 27 & 60 & 8 & 95 & 4.737 \\
\hline $\mathrm{RN}$ & 483 & 118 & 35 & 20 & 84 & 12 & 98 & 12.878 \\
\hline SE & 113 & 11 & 2 & 1 & 8 & 2 & 8 & 1.049 \\
\hline Sub-Total & 8.614 & 1370 & 296 & 263 & 941 & 118 & 1123 & 182.775 \\
\hline \multicolumn{9}{|l|}{$>10.000 \mathrm{ha}$} \\
\hline AL & 5 & 4 & 2 & 1 & 3 & - & 4 & 33.807 \\
\hline BA & 156 & 36 & 5 & 2 & 25 & 5 & 27 & 41.477 \\
\hline $\mathrm{CE}$ & 12 & 8 & 3 & 1 & 8 & - & 8 & 1.445 \\
\hline MA & 54 & 4 & - & 1 & 3 & - & 3 & 5.989 \\
\hline PB & 3 & 3 & - & - & 3 & - & 3 & 13.800 \\
\hline PE & 4 & 2 & - & 1 & 1 & - & 1 & 5 \\
\hline PI & 50 & 4 & - & 2 & 2 & - & 4 & 1.024 \\
\hline $\mathrm{RN}$ & 9 & 5 & 1 & - & 3 & 1 & 4 & 4.172 \\
\hline SE & - & - & - & - & - & - & - & - \\
\hline Sub-Total & 293 & 66 & 11 & 8 & 48 & 6 & 54 & 96.724 \\
\hline Total & 2.309 .085 & 114.060 & 30.454 & 40.187 & 44.539 & 9.134 & 98.203 & 746.895 \\
\hline
\end{tabular}

\section{B. Região Norte}

$<$ de 10 ha 
Continuação da Tabela 4

\begin{tabular}{|c|c|c|c|c|c|c|c|c|}
\hline \multirow{3}{*}{ Estado } & \multirow{3}{*}{$\begin{array}{c}\text { Total de } \\
\text { Estabelecimentos }\end{array}$} & \multicolumn{5}{|c|}{ Estabelecimentos Informantes } & \multicolumn{2}{|c|}{ Área Irrigada } \\
\hline & & \multirow{2}{*}{ Total $(*)$} & \multicolumn{4}{|c|}{ Método de Irrigação } & \multirow{2}{*}{ Informantes } & \multirow{2}{*}{ Área (ha) } \\
\hline & & & Inundação & Infiltração & Aspersão & Outros & & \\
\hline AP & 953 & 36 & - & - & 36 & - & 36 & 78 \\
\hline AM & 43.793 & 33 & 4 & - & 9 & 20 & 24 & 12 \\
\hline PA & 64.838 & 384 & 54 & 47 & 252 & 66 & 221 & 300 \\
\hline RO & 17.618 & 339 & 40 & 55 & 192 & 93 & 247 & 226 \\
\hline $\mathrm{RR}$ & 1.025 & 69 & 17 & 19 & 42 & 9 & 31 & 44 \\
\hline TO & 2.614 & 70 & 3 & 36 & 27 & 5 & 54 & 66 \\
\hline Sub-Total & 131.806 & 998 & 120 & 166 & 598 & 214 & 644 & 742 \\
\hline \multicolumn{9}{|l|}{10 a 100 ha } \\
\hline $\mathrm{AC}$ & 13.647 & 42 & 23 & 10 & 23 & 4 & 4 & 76 \\
\hline $\mathrm{AP}$ & 1.095 & 18 & - & 4 & 14 & - & 12 & 19 \\
\hline AM & 34.066 & 53 & 26 & 7 & 24 & 4 & 18 & 49 \\
\hline PA & 104.435 & 502 & 127 & 119 & 283 & 78 & 200 & 1.120 \\
\hline RO & 43.581 & 213 & 69 & 67 & 109 & 26 & 90 & 537 \\
\hline $\mathrm{RR}$ & 2.990 & 75 & 12 & 23 & 4 & 14 & 39 & 202 \\
\hline TO & 17.283 & 149 & 11 & 78 & 62 & 17 & 86 & 509 \\
\hline Sub-Total & 217.097 & 1052 & 268 & 308 & 519 & 143 & 449 & 2.512 \\
\hline \multicolumn{9}{|l|}{$100 \mathrm{a} 1.000 \mathrm{ha}$} \\
\hline $\mathrm{AC}$ & 5.860 & 12 & 6 & 3 & 9 & 2 & 2 & 604 \\
\hline $\mathrm{AP}$ & 1.152 & 5 & - & 1 & 4 & - & 3 & 12 \\
\hline $\mathrm{AM}$ & 4.910 & 24 & 8 & 1 & 14 & 2 & 13 & 29 \\
\hline $\mathrm{PA}$ & 34.476 & 190 & 51 & 66 & 93 & 15 & 40 & 1.493 \\
\hline RO & 14.874 & 108 & 43 & 29 & 66 & 9 & 28 & 227 \\
\hline $\mathrm{RR}$ & 2.810 & 68 & 11 & 25 & 34 & 4 & 40 & 726 \\
\hline TO & 19.565 & 240 & 51 & 119 & 76 & 31 & 110 & 5.901 \\
\hline Sub-Total & 83.647 & 647 & 170 & 244 & 296 & 63 & 236 & 8.992 \\
\hline \multicolumn{9}{|l|}{1000 a 10.000 ha } \\
\hline $\mathrm{AC}$ & 288 & 4 & 1 & 1 & 2 & - & 1 & 1 \\
\hline $\mathrm{AP}$ & 71 & 1 & - & - & 1 & - & 1 & 9.000 \\
\hline $\mathrm{AM}$ & 225 & 3 & - & 1 & 2 & 1 & 3 & 119 \\
\hline PA & 2.288 & 23 & 6 & 8 & 16 & - & 7 & 173 \\
\hline RO & 812 & 8 & 1 & 4 & 4 & 3 & 1 & 50 \\
\hline RR & 519 & 53 & 10 & 18 & 25 & 5 & 34 & 2.419 \\
\hline TO & 3.392 & 95 & 34 & 30 & 35 & 11 & 51 & 12.632 \\
\hline Sub-Total & 7.595 & 187 & 52 & 62 & 85 & 21 & 98 & 24.394 \\
\hline \multicolumn{9}{|l|}{$>10.000$ ha } \\
\hline $\mathrm{AC}$ & 31 & 1 & - & - & 1 & - & 1 & 32 \\
\hline AP & 4 & 1 & - & - & 1 & - & 1 & 10 \\
\hline AM & 28 & - & - & - & - & - & - & - \\
\hline PA & 162 & 9 & 2 & 3 & 3 & 2 & 5 & 1.711 \\
\hline RO & 69 & 3 & - & - & 3 & - & 1 & 1 \\
\hline RR & 51 & 2 & 2 & - & - & - & 2 & 2.270 \\
\hline TO & 83 & 13 & 9 & 1 & 3 & 1 & 10 & 42.361 \\
\hline Sub-Total & 15.618 & 29 & 13 & 4 & 11 & 3 & 20 & 46.384 \\
\hline Total & 455.763 & 2.913 & 623 & 784 & 1.509 & 444 & 1.447 & 83.024 \\
\hline \multicolumn{9}{|l|}{ C. Região Sudeste } \\
\hline$<$ de 10 ha & & & & & & & & \\
\hline ES & 23.492 & 4.051 & 711 & 359 & 3.172 & 105 & 3650 & 6.392 \\
\hline MG & 169.638 & 17.608 & 4.587 & 3.861 & 9.536 & 1.082 & 14.636 & 25.280 \\
\hline $\mathrm{RJ}$ & 28.439 & 8.040 & 1.016 & 900 & 6.204 & 196 & 7.544 & 12.070 \\
\hline SP & 65.303 & 14.183 & 860 & 1.251 & 11.774 & 1.144 & 12.416 & 30.301 \\
\hline Sub-Total & 286.872 & 43.882 & 7.174 & 6.371 & 30.686 & 2.527 & 38.246 & 74.043 \\
\hline 10 a 100 ha & & & & & & & & \\
\hline ES & 43.412 & 9.181 & 2.084 & 1.084 & 6.970 & 211 & 8.205 & 45.153 \\
\hline MG & 246.286 & 21.200 & 7.416 & 4.398 & 10.668 & 1.417 & 13.310 & 83.904 \\
\hline $\mathrm{RJ}$ & 20.005 & 3.890 & 1.250 & 662 & 2.292 & 74 & 3.348 & 20.593 \\
\hline SP & 119.209 & 11.704 & 1.148 & 1.310 & 9.739 & 931 & 9.067 & 110.418 \\
\hline Sub-Total & 428.912 & 45.975 & 11.898 & 7.454 & 29.669 & 2.633 & 33.930 & 260.068 \\
\hline 100 a 1.000 ha & & & & & & & & \\
\hline ES & 6.102 & 1.432 & 362 & 142 & 1.069 & 63 & 1.280 & 34.468 \\
\hline MG & 75.805 & 8.124 & 1.884 & 1.273 & 5.449 & 516 & 6.127 & 138.315 \\
\hline $\mathrm{RJ}$ & 5.011 & 887 & 368 & 191 & 459 & 25 & 714 & 28.803 \\
\hline
\end{tabular}


Continuação da Tabela 4

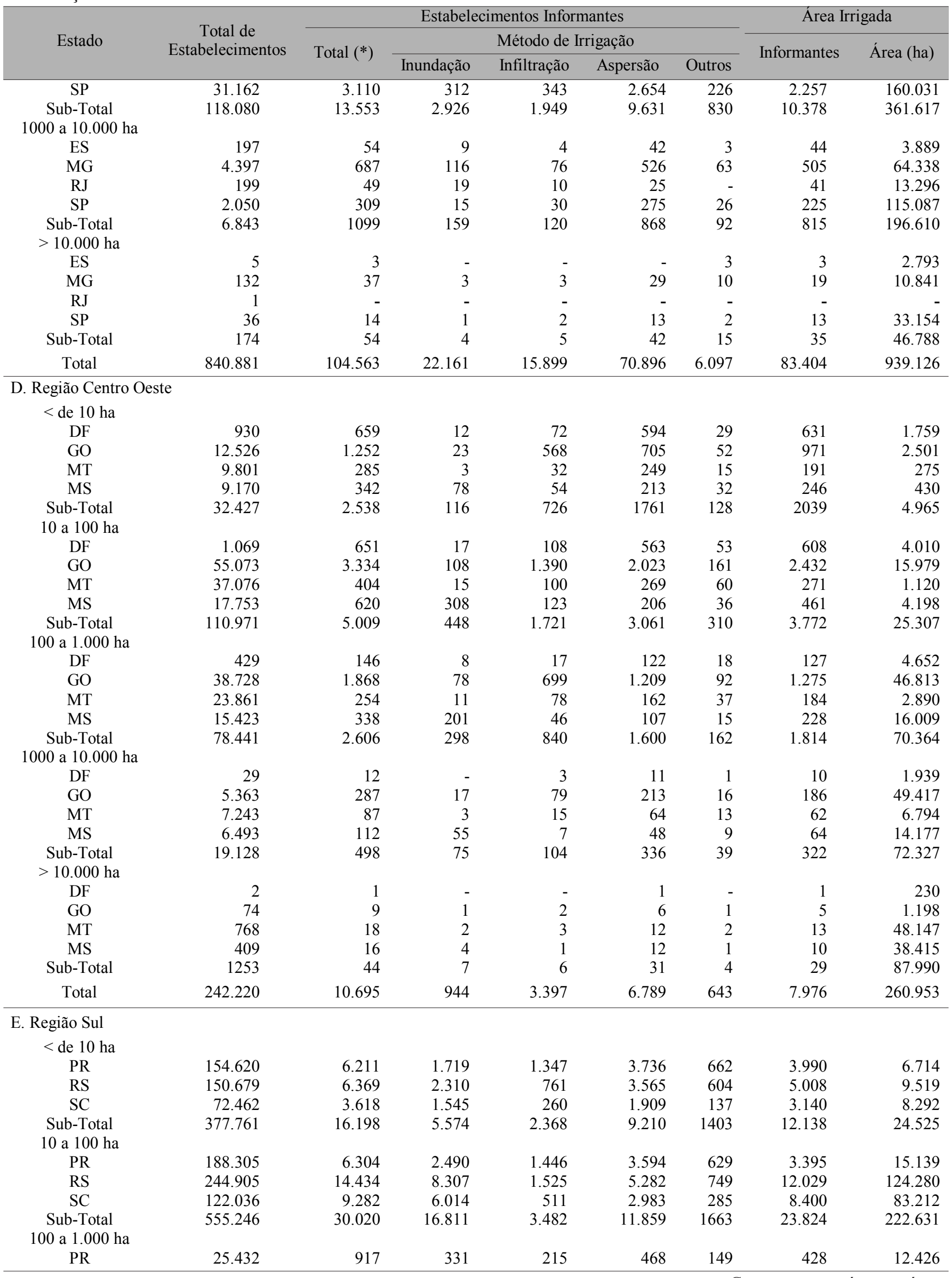


Continuação da Tabela 4

\begin{tabular}{|c|c|c|c|c|c|c|c|c|}
\hline \multirow{3}{*}{ Estado } & \multirow{3}{*}{$\begin{array}{c}\text { Total de } \\
\text { Estabelecimentos }\end{array}$} & \multicolumn{5}{|c|}{ Estabelecimentos Informantes } & \multicolumn{2}{|c|}{ Área Irrigada } \\
\hline & & \multirow{2}{*}{ Total (*) } & \multicolumn{4}{|c|}{ Método de Irrigação } & \multirow{2}{*}{ Informantes } & \multirow{2}{*}{ Área (ha) } \\
\hline & & & Inundação & Infiltração & Aspersão & Outros & & \\
\hline RS & 30.727 & 5.015 & 4.479 & 148 & 428 & 130 & 4.505 & 473.792 \\
\hline $\mathrm{SC}$ & 8.231 & 544 & 202 & 38 & 329 & 18 & 450 & 18.810 \\
\hline Sub-Total & 64.390 & 6.476 & 5.012 & 401 & 1225 & 297 & 5.383 & 505.028 \\
\hline \multicolumn{9}{|c|}{1000 a 10.000 ha } \\
\hline PR & 1.433 & 84 & 19 & 9 & 56 & 16 & 43 & 12.610 \\
\hline RS & 3.056 & 984 & 896 & 15 & 53 & 44 & 886 & 299.517 \\
\hline $\mathrm{SC}$ & 505 & 31 & 5 & 2 & 26 & 2 & 23 & 3.712 \\
\hline Sub-Total & 4.994 & 1099 & 920 & 26 & 135 & 62 & 952 & 315.839 \\
\hline \multicolumn{9}{|l|}{$>10.000 \mathrm{ha}$} \\
\hline PR & 17 & 1 & - & - & 1 & - & 1 & 1 \\
\hline RS & 16 & 9 & 9 & - & - & - & 9 & 28.569 \\
\hline $\mathrm{SC}$ & 3 & - & - & - & - & - & - & - \\
\hline Sub-Total & 36 & 10 & 9 & - & 1 & - & 10 & 28.570 \\
\hline Total & 1.002 .427 & 53.803 & 28.326 & 6.277 & 22.430 & 3.425 & 42.307 & 1.096 .593 \\
\hline
\end{tabular}

'Fonte: CENSO AGROPECUÁRIO 1995-1996 - NÚMERO 1 - BRASIL

${ }^{*}$ ) Inclusive os estabelecimentos que declaram mais de um tipo

porcentagem da área irrigada (361.617 ha) encontra-se nos estabelecimentos com área compreendida entre 100 e 1.000 ha; já os estabelecimentos com mais de 10.000 ha irrigam apenas $5,0 \%$ da área total (46.788 ha).

Quando se analisa o número de estabelecimentos que fazem o uso da técnica de irrigação, nota-se que $86,0 \%$ têm menos de 100 ha e apenas $0,1 \%$ mais de 10.000 ha, ou seja, a tecnologia da irrigação é praticada, em maior escala, na pequena propriedade, tal qual o Nordeste.

\section{Região Centro-Oeste}

Os estabelecimentos com indicação de uso de irrigação e área total por estado da região Centro-Oeste do Brasil, segundo grupos de área total, são apresentados na Tabela 4D. Com relação à área total irrigada, esses grupos apresentam 1,9, 9,7, $27,0,27,7$ e 33,7\% da área irrigada, respectivamente; neste caso, a maior porcentagem da área irrigada (87.990 ha) encontra-se nos estabelecimentos com áreas maiores que 10.000 ha; já os estabelecimentos com menos de 10 ha irrigam apenas $1,9 \%$ da área total (4.965 ha). Conforme se observa, a configuração nessa região se assemelha à região Norte, sendo oposta ao Nordeste e Sudeste do Brasil.

Ao se analisar o número de estabelecimentos que fazem uso da irrigação, nota-se que $46,8 \%$ são estabelecimentos cuja área está compreendida entre 10 e 100 ha. Do total de estabelecimentos que fazem irrigação, apenas $0,4 \%$ tem área com mais de 10.000 ha.

\section{Região Sul}

A Tabela 4E mostra os estabelecimentos com indicação de uso de irrigação e área total por estado da região Sul do Brasil, de acordo com os grupos de área total. Esses grupos apresentam 2,2, 20,3, 46,1, 28,8 e 2,6\% da área irrigada, respectivamente. A maior porcentagem da área irrigada (505.028 ha) encontra-se nos estabelecimentos com área entre $100 \mathrm{e}$ 1.000 ha, enquanto aqueles com menos de $10 \mathrm{ha}$, irrigam apenas $2,2 \%$ da área total ( 24.525 ha) e os que têm área maior que 10.000 ha, irrigam somente $2,6 \%$ (28.570 ha). Observa-se que a configuração nessa região é completamente diferente das demais regiões do país.

Quanto ao número de estabelecimentos que utilizam irrigação, 55,8\% apresentam área entre 10 e 100 ha, e apenas $0,02 \%$ tem área maior que 10.000 ha.

\section{CONCLUSÕES}

1. A análise demonstra a importância do uso das estatísticas do Censo Agropecuário sobre irrigação no país; assim, é possível aprofundar os conhecimentos sobre a extensão da área irrigada e o uso dos métodos de irrigação; os resultados mostram quais as regiões, e dentro de cada região, os estados onde a tecnologia da irrigação tem maior importância. É possível, também, avaliar o tamanho das propriedades que utilizam a irrigação com maior intensidade.

2. O trabalho demonstrou que a região Sul apresenta a maior área irrigada, representando $35 \%$ da área irrigada total no país. O Rio Grande do Sul é o Estado com a maior área irrigada (935.677 ha).

3. No Nordeste, onde a irrigação é importante devido a semi-aridez da região, esta técnica representa 24,1\% (751.887 ha) da área total irrigada no Brasil, com a Bahia se destacando com a maior área irrigada (209.705 ha) entre os estados.

4. Métodos de irrigação por superfície predominam em duas regiões - Nordeste $(56,8 \%)$ e Sul $(57,2 \%)$ - enquanto a aspersão é mais usada no Sudeste $(66,9 \%)$ e Centro-Oeste $(63,1 \%)$.

5. O resultado da análise aqui desenvolvida, recomenda que o Censo Agropecuário deve melhorar o conceito de irrigação e incluir a irrigação localizada em seus levantamentos; a compatibilidade dos dados censitários com aqueles publicados (Christofidis, 1999) coloca em dúvida a tese do amplo conceito de irrigação usado no censo, proposta por Souza et al. (1994).

\section{LITERATURA CITADA}

Brasil. Ministério da Agricultura. Programa Nacional de Irrigação . Resenha setorial da irrigação no Brasil. Brasília, 1989. 87p. 
Christofidis, D. Recursos hídricos e irrigação no Brasil. In: Workshop Disponibilidade de Água e Irrigação no Nordeste, 1999, Brasília. Texto... Brasília: ISPN, 1999.34p.

Hernando, H.C. Papel do governo e da iniciativa privada no desenvolvimento da agricultura irrigada na Espanha. In: Seminário Internacional de Políticas de Irrigação e Drenagem, 1997, Brasília. Anais... Brasília: MMA/SRH, 1998. 232p.p.125-165.
IBGE - Instituto Brasileiro de Geografia e Estatística. Censo agropecuário - 1995-1996. Rio de Janeiro, 1998.

Souza, H.R.; Figueiredo, A.P.; Machado, R.RT.; Ramos, A.S. Agricultura irrigada e desenvolvimento sustentável no Nordeste do Brasil. Brasília: Secretaria de Planejamento, Orçamento e coordenação da Presidência da República, 1994. GTIV-IV.3. Projeto ARIDAS. Uma estratégia de desenvolvimento sustentável para o Nordeste. 